\title{
Reclassifying Housing Delivery Delay Classification
}

\author{
Chang Saar Chai ${ }^{1} \&$ Aminah Md Yusof ${ }^{2}$ \\ ${ }^{1}$ Housing Research Network (HORN), Faculty of Civil Engineeering, University of Technology Malaysia, \\ Malaysia \\ ${ }^{2}$ School of Graduate Studies, University of Technology Malaysia, Malaysia \\ Correspondence: Chang Saar Chai, Faculty of Civil Engineering, Universiti Teknologi Malaysia, 81310 UTM \\ Skudai, Johor, Malaysia. Tel: 601-0808-8067. E-mail: cschai2@live.utm.my
}

Received: April 25, 2013

Accepted: July 24, 2013

Online Published: October 15, 2013

doi:10.5539/ijbm.v8n22p107

URL: http://dx.doi.org/10.5539/ijbm.v8n22p107

\begin{abstract}
This paper intends to analyze, define and reclassify delay in housing delivery system in Malaysia. The late delivery in construction project has become common problem in the industry, especially housing project in Malaysia. As old school approaches are not effective to mitigate the delay occurrence, there is a need to rethink and reclassified the delay factors so that the housing delivery delay could be effectively avoided. The aim of this paper is to reclassify the housing delivery delay factors in order to simplify the delays detection and mitigation provisions. The delay factors are classified into structural, institutional and cultural. A comprehensive literature review from various sources has made to carry out the study. The study found that construction stage is the major contribution to housing delivery delay. Besides, the study also identified 18 critical structural delay factors, 3 institutional delay factors, and 3 cultural delay related factors in Malaysian housing industry.
\end{abstract}

Keywords: delay classification, housing delivery delay

\section{Introduction}

Construction industry is denoted as the key player in a country development. The industry acts as a catalyst for the economy through the creation of wealth to other industries. However, the complexity nature of the construction industry is aggravated by its reactive characteristic are generally due to its fundamental business core and temporary relationship among the players (Knight, 2001). The fragmented and sequential way of working has creates endless problems in the industry. The project delivery from inception to hand over involves various parties which deteriorate the information delivery, results in communication failure and delay. Lately, the construction projects have tended to become time constrained, especially in housing sector.

Housing sector has been one of the construction industry's significant contributors. The sector becomes important for its role as physical output contributors as well as provider of basic human need. As the product of housing industry become significant socially and financially, the need to ensure the efficient and effective delivery is become inevitable.

"Time is essence" and 'time is revenue' are vital philosophies in the construction industry and housing sector. To complete the projects on time and within schedule is as essential benchmark for proprietor and executors as well as house buyers. In housing projects, the deliverance completed housing units is crucial in pursuit of accomplishing 'promise' as stipulated in the Sales and Purchase Agreement between developers and buyers. Housing projects often experience delay and it can happened in whatever path along the course of its delivery.

Delay investigates in many studies such as Tan (2010); Ahmad Tarmizi (2003); Ng (2001); and Wan Hasitinaziah (2001). Delay advocates a more general definition such as "time overrun from the planned or contract schedule. In specific delay is related to the critical activities. Many conclude that delay is defined as the postponement of completion work as compared to the baseline schedule or contractual schedule. Delay in construction projects undertaking has been addressed substantially in construction and project management. The classification of delay and its impact on the project's performance and its stakeholders has been thoroughly investigated. Similar effort seems to be less appreciated in the analysis of housing sector despite numerous problems associated with the sector.

In Malaysia, there are complaints regarding abandoned projects, poor workmanship, delay in issuance certificate 
of fitness, handing over delay, developer reluctant to pay compensation for late delivery, interest charged by the developers due to late progressive payments and payment problems related to maintenance charges are common as highlighted by the Ministry of Housing and Local Government Malaysia (MHLG, 2007). The problems attribute by different parties which lead by lack of comprehensive analysis on the sources and how the problem should be addresses. The sources of delay should be promotes in order to analyze and classifying so that a more approachable manner is expected.

\section{Delay and Its Classification}

Delay in construction project is often results from miscommunication between the construction players, developers, consultants, contractors, subcontractors and others. These communication failures and broken information chain normally can be avoids through the use of critical path scheduling, which specific work, timetable and logical sequence of construction processes been analyzed and followed by the team. As delay been concerned, it is critical to fully understand the delay and how it affects the construction life cycle, the term of delay needs to be defines.

Generally delay is referring to something late or slow, postpone or defer (Oxford Dictionary, 2013). Previous researcher has defined delays by their own meaning, however it brought similar philosophy. The delays in construction industry have been particularly defined in terms of contract delay, construction, client and even effects of delays. There is no precise meaning of 'delay' in construction contracts but represent the condition of project execution. Though, the term is widely used to determine the occurrences or events that the extension of time of any activities of a project (Braimah, 2008).

Assaf et al (1995) and Abd. Majid (2006) define delay as the time overrun either beyond specify contract duration or beyond the date that all parties agreed upon for project delivery. Bartholomew (1998) has further defined delay as slowing down of work without stopping it entirely. A different view of delay has been introduced to the public where Bartholomew emphasize on the slow progress rather than stoppage of work as many others researchers have included stoppage of work into construction delay in which stoppage of work results in extension of project delivery.

In fact construction delay is defined as any additional time that required to the execution period that stipulated in the contract or increases of duration beyond the date of completion within the contract period (Nunally, 1978; Bramble, 1987). Majid, I. A. (1997) describes delay as a loss of time. As 'times' are usually refer to the duration for a construction project, the project delay means that the project cannot be completed within the original planned schedule which is usually followed by the cost overrun. To recover such costs, claims often arises in several ways to ensure adequate extension of time and sufficient reimbursement. The reimbursement of claims involves claimants/defendants to identify and quantify such loses. The definition of construction delay which introduce by Pickavance (2005) had covered the following;

- progress delay that caused the postponement to completion dates;

- prolongation of contractor's time-related costs;

- progress delay that result in contractor's loss;

- reduction in productivity that caused loss to contractors.

The critical factors affecting the timely delivery of housing might be associated with tightened financial condition within a state. Another factor encouraging delays in the process is the periodic payments from the customers while on the other hand there are significant and continuous expenditures on the part of the industry. Changes in the climatic conditions also affect the planned schedules for construction thus initiating delays in the timely delivery. Though construction projects are always complex and segmented, thus problems will arise that are not foreseen in the original contract, and so other legal issues such as variation orders and workers levy. Before analyzing construction delay, it is essential to understand the classification of delays. According to Kraiem and Diekman16, delays can be classified into four categories: excusable, excusable with or without compensable and non-excusable. 


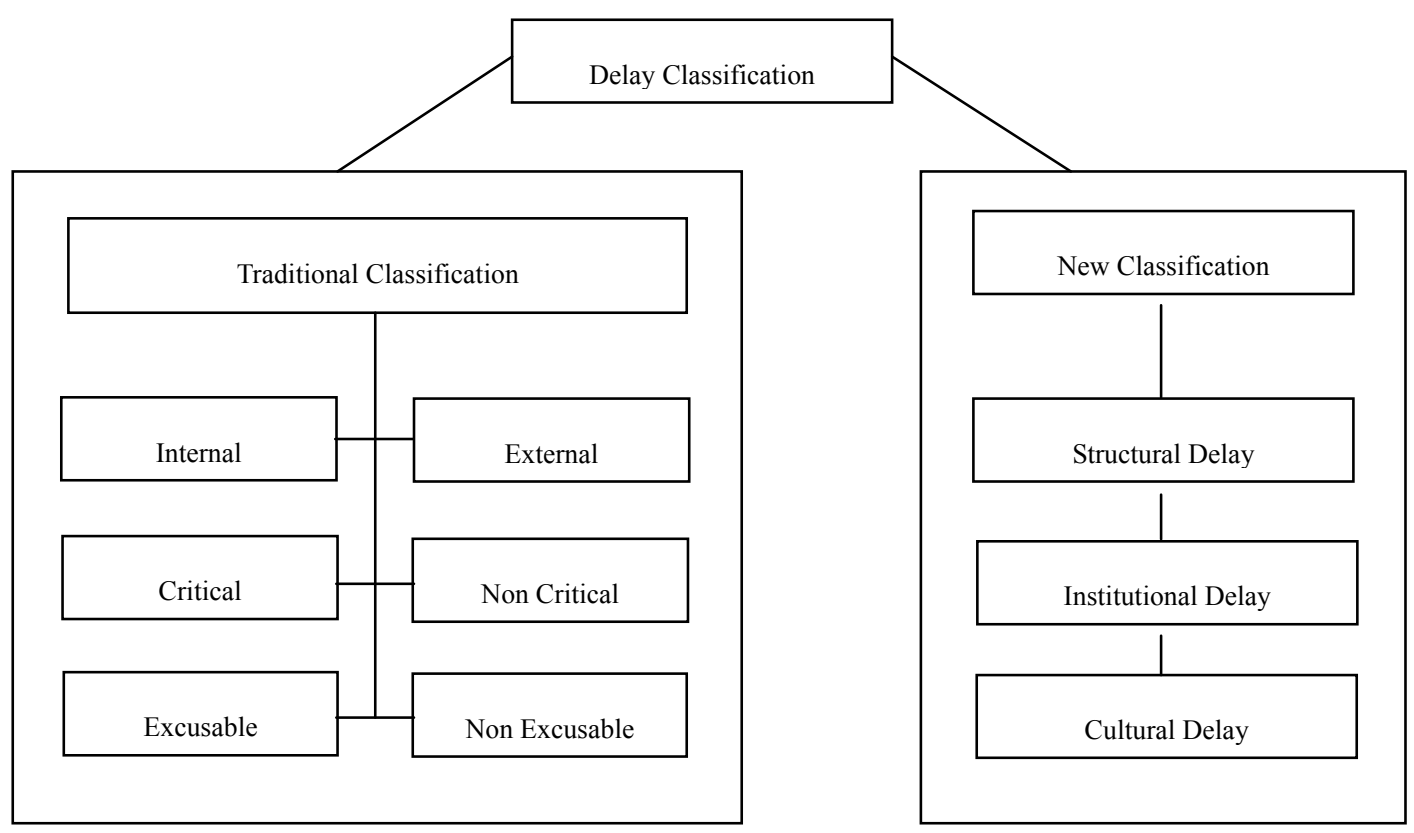

Figure 1. Delay classification in construction industry

According to figure 1, the classifications that have been discussed and studied by the researchers are classified as traditional classification method while the latest classifications that involve the adoption systematical, legislative and cultural will be classified as new classification. As cost becomes the most important issue in project management, delay is seen as cost bearer. Thus, the traditional classification tends to focus on cost implication in which the level of criticality had become cost domain without taking any other consideration of the delay factors attributors. As housing industry develops, the time, cost and quality issues are not the only consideration of the construction players, but includes sustainability, customer satisfaction, public relationship, and environmental criteria. Thus, the traditional classifications become less appropriate to address the delay factors.

Defining and classifying the factors of delay according to structural, institutional and cultural intends to provide another platform to identify the factors of delay in different trade rather than the previous traditional classification as shown in figure 1 . The new classification of the delay will look into the structures of the project organization, the institutional influences and the behavior of the players involved. The need to reclassify delay is crucial as different sources attributed by different parties. A new approach to classification will enable a much proper mitigation plan to be adopted at the same time address the delay in housing delivery system. The reclassification of delay is significant to the construction industry due to the construction delay had been recently become a norm in the industry. Therefore, this approach is able to open a new arena to review the current construction delay in the industry, especially housing.

In order to provide appropriate mechanism in solving delay in housing delivery, the new classification (structural, institutional, cultural delay) could be further classify through the traditional method in order to provide a more comprehensive coverage to the delay factors as shown in figure 2. 


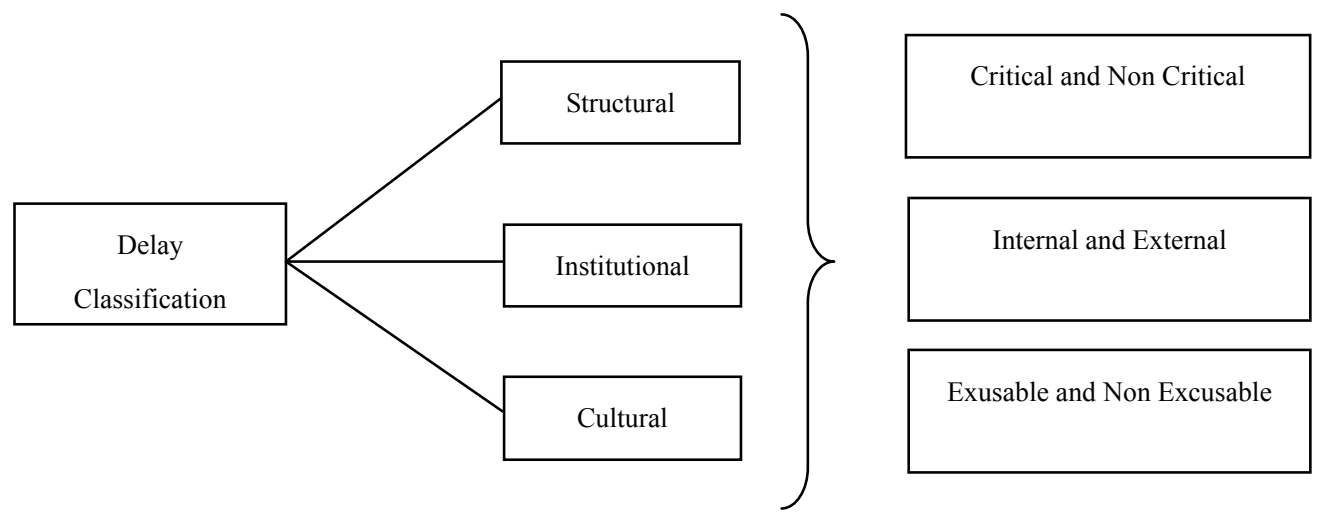

Figure 2. Delay classification

Delays can be captured through the structural system in an organization, players involved in the construction, development approval processes, institutional influences, design related issues, culture, economy development, external factors and others. Although the delays factors have been identified for decades, but delay still remain common phenomenon in construction industry. This is most probably due to the root causes of construction delays have not been treated and educated properly to the public stakeholders. Through the classification of structural, institutional and cultural delay, the construction delay can be treated systematically through organization system, government institutional procedures and construction players' cultural behavior. From there, traditional classification method able to further classify the delay factors again to allocate appropriate measure to be taken. It is easier to mitigate the sub divided delay factors rather than provide mitigation plan which covered the whole picture.

The term of structural, institutional and cultural are widely use in social science research as it involved variety topics in the management research. Researchers are struggling to define them as there are various thoughts of defining structural, institutional and cultural in different research arena. However, the definition of structural, institutional and cultural in term of delay has not been discovered before. As such, there is a need to understand the fundamental of the definition before the new classification could be defined. Various sources of definition had been discovered, either dictionaries or previous research philosophy.

The following section explains the definition of structural delay, institutional delay and cultural delay where they are derived from.

\subsection{Structural Delay}

The Oxford Dictionary defines structure as the relationship between the elements (factors, members (people), processes, procedures, steps, parts, etc) of something complex which constructed from several differential parts. However, structure also been describes as the elements had been put together in a particular way to form something (The Free Dictionary, 2013). Structure also been defines as a complex system which should be considered as a whole rather than of any single part of that particular organization or system (The Online Dictionary, 2013). According to Business Dictionary (2013), the identifiable elements in a particular organization or a system are refer to components, entities, factors, members, parts, steps and other which form the stability of the organization. The definition of structure remains elusive and contested due to struggling effort by many to put on a workable definition to the structural delay. The understanding of structure will further strengthen by elaborating and discussing through the following part.

The Oxford Dictionary (2013) defines structural as the arrangement or the relationship between the elements of housing sector. It is interrelationship to the others definition of "structure" where as researchers had defined it as the relationship of the elements in an organization or a system. In addition to the Business Dictionary, the structural variation refers to the organization or economy recurring change due to seasonal patterns or long time trends. It has further defines structural analysis as an examination of the different elements that make up an organization in order to discover their interrelationship and importance in the realization of its aim. Structural analysis can be used in any kind of system, text or material and applies to social science, humanities as well as hard science research through different connotations, for example civil engineering, real estate, medical, information system, journalism, organizations, structuralism, educations and many others related fields. The role of structural analysis is more than examining the elements; it is about to breaking down the system or 
organization's complexity in order to inspect any level at different perspective.

As the term organization has been repetitively highlighted in the definition of structure, it is essential to study and to explore the term in the process of formulation a new classification of delay. According to Oxford Dictionary, organization is defines as a group of people with particular interest. The organization is normally has a collective goals in term of social entity which includes corporations, governments, non government bodies, partnerships, cooperatives and others. The organization might be either operates in both the public and private sectors. Moreover, the organizations in construction industry are segmented due to the formation of the organizations are temporary and fragile bonding between the parties involved. Construction management teams or project management teams are formed through the representatives from the developer, consultants (Architect, Landscape Architect, Civil and Structure Engineer, Mechanical and Electrical Engineer, Quantity Surveyor, Interior Designer) main contractor, and nominated sub contractor. This temporary team is usually defending their own interest in the project organization while at the same time meeting the same goal to deliver the project successfully. As a result, the project organizations are tentatively problematic based due to the reason mentioned above.

After the structural analysis of delay has been studied, the next step is to define structural delay in which the definition will be defined based on the fundamental of "structure". It could be derive that the structural delay is referring to the delays resulted from the organization itself, either system, managerial or structure deficiency which causing any kind of time postponement. In other words, structural delays are identifiable in any form of organizational system through the elements and factors that forming the structure of the organization. In terms of structural delay in housing delivery system, it is expected to identify the delays in development approval stage, construction stage and handing over stage as well as the organization involved will be concerned. The organizations in the housing delivery system are referring to the local authorities, developers, consultants and contractors.

\subsection{Institutional Delay}

The term institution has been extensively use in social science research, reflecting the use of the concept in some other disciplines are broad, including philosophy, economics, anthropology, sociology, politics and geography (Geoffrey, 2006). According to Oxford Dictionary, institution is defines as an establishment of law or practices. In term of sociology, institution is describes as a well established and structured pattern of behavior hips that been adopted as a part of a culture. It could be further defines as an established law, custom or social order in a particular society (The Free Dictionary, 2013; The Online Dictionary, 2013).

Business Dictionary shares a similar terminology in terms of the behavior of the organized pattern in self regulating the principles in accordance to general acceptance norm which involved political, economical and so on. The political institutions are usually involved with competition power in regulating the rules and regulation while economical institutions are related to economical production of goods and services.

As housing delivery system is concerns, the political institution of Malaysia has regulated a series of rules and regulation in order to ensure a quality supply in housing production. Moreover, the National Housing Policies has been introducing to delineate the basis of housing planning and development at federal, state and local levels. It is also means to provide adequate, comfortable, quality and affordable housing to improve the wellbeing of the citizens in accordance to the Tenth Malaysia Plan (10MP) in providing adequate, safe, healthy and harmonious living environment equipped with complete public amenities and recreation facilities (National Housing Policy Malaysia). There are 79 preeminent Acts and Regulations incorporate to housing industry are systematic that covered the entire process of housing delivery system which including the Local Authority power, planning process, construction safety, workers welfare, quality, arbitration, payments and etc. The full frame of Acts and Regulations helps to protect the relevant parties and to ensure the housing is delivered in legal and fair.

Although Rules and Regulations aim to protect and to control the housing delivery system, but there are studies showing the housing delays are normally resulted from the excessive Rules and Regulations. According to Audit Commission of Great Britain (2005), delay in housing delivery is due to the incompetent of Local Authority in handling housing approval and confusion in housing planning framework.

As such, it could be concludes that the institution delay is referring to the delays resulted in the process, discrepancies, uncertainties of the institutional evaluation in statutory requirement, procedure and approval, due to excessive Acts and Regulations to comply. According to Hemanta et al. (2012) local authority related and technical issues are the most important problem in India construction projects as many have overlook the duration taken for the development approval. Mohammed in the other hand studies the delay in public utility 
projects in Saudi Arabia which finally discovered that the local authorities are responsible for the project delay other than contractor and consultant.

\subsection{Cultural Delay}

Culture is identifies to be one of the most difficult and complex term to be understands. This is mostly because of the term has been widely used in different arena which sometimes conflicting. Culture as defines by Hofstede. G (1991) is the behaviors, beliefs, values and symbols that accepted by a group of people in their life. Merriam Webster Dictionary has further defines the culture as a set of attitudes, values, goals, and practices that characterize within an organization or institution. In general, most of the dictionary and researchers define culture as a behavior or belief in a particular society which included societal aspect like customs, norms, rules, products and others which treated as social norms (The Online Dictionary, 2013). Anthropologist Edward B. Taylor (1889) offers a broader definition; describe culture as the capabilities and habits by the member in a society which includes knowledge, belief, arts, custom, law and others.

In the context of organization culture, it is a concept, yet incredibly difficult to measure which involved the social standards, values and belief that people are holding which bind to that particular organization. Besides, it could be recognized as a set of behavior that the people embody culture in the elements of the organizations. The behavior of the organization includes the expectation, experience, philosophy, and values that hold the organizational culture together. The organizational culture is normally learned, either internally or externally. The culture might learn internally from the management decision making, monitoring, controlling and technologies of the organization, especially to the junior level and middle executive level. The learning cycles will be continued to ensure the new generation of the organization will be practicing the same. Moreover, organizational culture is commonly held rather than shared. Beliefs, attitudes and behavior are hardly to be shared with some others, but it could be derived through consensus on logic thinking and behave during some situation in organization. In reality, each organizational culture is unique to the members in the organization, and the characteristic might differ in the organization's departments, levels and members.

In terms of project organization, the organization members are the representatives from their company who enter the temporary team and bring their culture with them and embody in the new formed organization. In addition, the performance of the organizational culture is directly related to the business performance (The Business Dictionary, 2013).

Consequently, cultural delay is the delays due to the organizational culture; behavior, practices, attitudes of the decision maker, interrelated to the organization structure in making decision. The classification of the structural delay is able to pinpoint the area of improvement since the culture of an organization can be easily altered compared to the systems and policies. The relationship of culture and organization could be defined through mathematical approach as shown in figure 3 . The organization is a subset to culture, illustrates that the elements of the organization formation brought different characteristic of culture. Thus, there are numerous possible factors that lead to cultural delay as each decision maker from different organizations is varied.

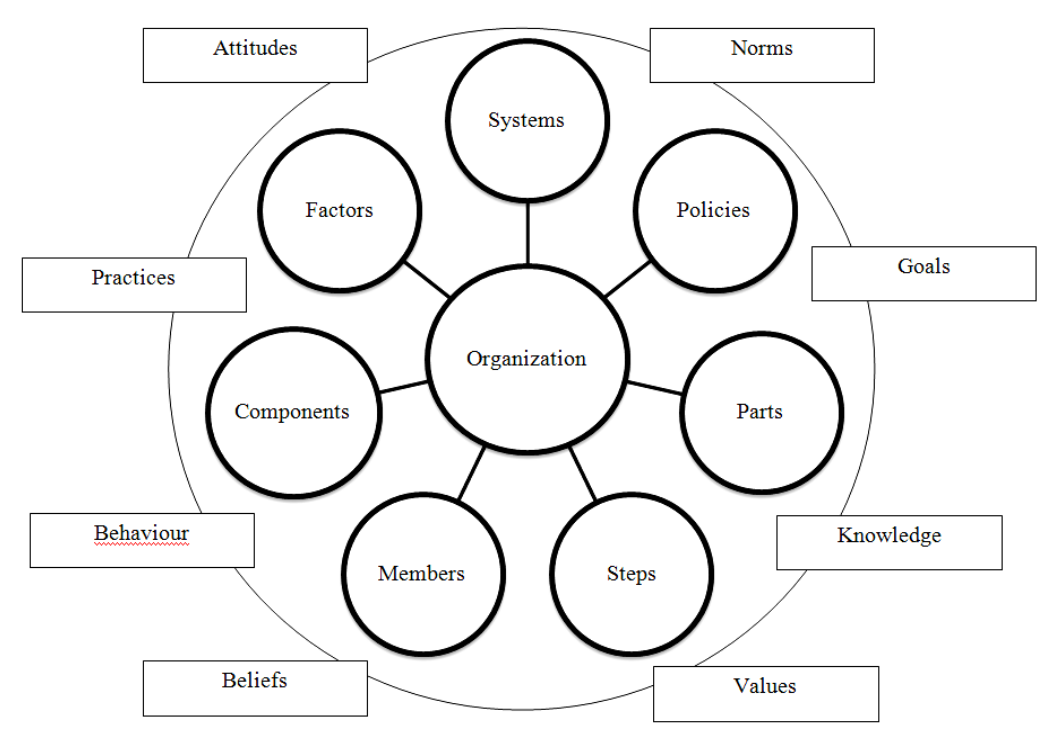


Figure 3. Defining cultural delay

\section{Methodology}

The study follows the sequence of reviewing of the delay in housing delivery system which include three (3) stages of delivery process, development approval stage, construction stage and handing over stage. The review thus helps the identification of delays factors which is important for the questionnaire preparation. Questionnaire is prepared to gain a deep understanding on scale of delay attributed by each party. The local authorities have been asked to help the identification of factors or causes of delay by the developers and consultants. To get fairer opinion the consultants/developers and contractors kindly are required to comment on the authority in delay at the development approval stage.

\section{Analysis and Discussion}

The survey on four (4) parties has been carried out via structured questionnaire. Principal Component Analysis (PCA) had been selected to analyze the criticality of the delay factors to the housing delivery system. PCA had been run separately towards three (3) different housing delivery stages. There are 97 delay factors which identified by preceding researchers from various studies had been listed and Likert Scale were given to collect relevant opinion from the respondents. By referring to Appendix A, 78 delay factors had been extracted from PCA, arranged in three (3) components namely structural, institutional and cultural meanwhile 24 delay factors are considered critical as the factor loadings are above 0.8 (Appendix B). Out of 24 critical delay factors, eighteen (18) factors are classified under structural delay, and three (3) factors each are classified under institutional and cultural delay. It can be concluded that the major delay factors contributed to housing delivery system in Malaysia is resulted in construction stage which mostly related to structural delay.

From the Appendix A, there are 27 delay factors contributed to development approval stage delay, 42 factors contributed to construction delay and 9 factors contributed to handing over stage delay. The analysis illustrated that the uncertainty of the statutory requirement has been highly recognized as major contribution to housing delivery delay in development approval stage which had been classified into institutional category as it involves legal institutional process. The argument that development approval processes have not been made public causes difficulties in ascertaining documents needed to be submitted. This is related to the authority system that had not been revised since independent until the introduction of One Stop Center (OSC) in April 2007. However, the launching of OSC is meant to improved the development approval duration by shorten the approval periods; the issue of uncertainty of statutory requirement still exist as it had not been taken into serious consideration so far. Moreover, respondents highlighted that the uncertain requirements which imposed after the submission had prolong the development approval duration as some imposed requirements were not been accepted by the developers such as provides some facilities to the public in proposed development area. The unwillingness to incur extra costs in performing social corporate service might end up in court battle.

Despite, late in revising and approving design documents by owners is one of the major contributors to development approval delay as well. Respondents had chosen to classify this factor as structural meanwhile there are suggestion to categorize it under institutional category. Structural delay is defined as delays resulted from the organization itself, either system, managerial or structure deficiency which causing any kind of time postponement. As late in revising and approving by owners are usually refers to developers that unable to make decision which sometimes developers themselves are confused with their own aims and objectives in that proposed development. The attitude of late decision making by owners obviously causing difficulties in local authorities to proceed with the development approval. Therefore, some portion of respondents had related this factor with institutional delays.

As major delay factors are concentrated at construction stage, it could be understood that construction stage in housing delivery system contributed to the delay the most. This is mostly due to many activities involved in construction stages which results in poor professional management in handling those activities thread. Out of 42 delay factors in construction stage, 14 factors are extracted with 5 critical factors that contribute factor loading more than 0.8 which are, delay in site mobilization $(0.855)$, unreliable subcontractor $(0.854)$, site labor turnover (0.873), poor site management and supervision $(0.862)$ and nationality of labors $(0.851)$. These factors are classified under structural delay factors as majority of the respondents are given similar responses that organizational failure leads to the occurrence of these factors. The construction delays normally incur with the increase of project budget and low motivation to the project team.

There are two (2) critical delay factors detected in handing over stage, handover packaging and appliances defects which recorded 0.899 and 0.876 factor loading. Developers are highly recommended to hand over the product professionally by providing good hand over packages. Due to certain circumstances that handover 
packaging is done in unprofessionally results in unnecessary conflict among the purchaser and developer staffs. Case reported such as insufficient room keys, wrong keys handover to purchaser, and wrong attachment of user manual and so on. This is mostly due to the carelessness of the staff in sorting out the handover packages.

The structural delay is dominating the housing delivery delay factors as 18 of critical delay factors are fall into structural delay category. It could be concluded that the organization system, managerial and structure of the organization is crucial in determine the project delivery. However, the managerial system had sometimes become culture of the organization that difficult to alter after long period of practicing. Besides, the reformation of managerial system is not easy to be conducted as it required cooperation from the staffs in the organization itself. The most tedious is that the project management organization is formed by several organizations from different company. Therefore, the reformations of organizational system have to be conducted in each particular organization that joins the project team to improve the efficiency in mitigating housing delay. However, it is impossible at current stage that majority of the organizations are reluctant to change due to unforeseen risk and they had been used to conventional managerial system.

\section{Conclusion}

The study shows the delay occurs at different stages of delivery process which inter related to construction players. The introduction of new delay classification is essential to provide a new discussion platform in determining the nature of delay in housing delivery system. As many had restricted in old school terminology that delay could be identified through monetary terms, however, the characteristic of delays had been neglected. Whilst determining delay in terms of structural, institutional and cultural, delay analysis either "as-planned technique", "as-built technique", "time impact technique" or "window snapshot technique" and etc could be altered to match the new classification. Through the new classification of the delay factors, the mitigation plan could be establish through the systematic structure of the organization, institutional and cultural approach. The introduction of new delay classification is the first milestone to introduce a better delay mitigation framework through the exploration of organizational, institutional and cultural characteristic of delay. As previous had said, the occurrence of delay in construction industry are inevitable, it is the matter of how the delays been manage and mitigated.

\section{Acknowledgements}

We would like to thank Innovative Construction Alliance (ICON), Faculty of Civil Engineering, Universiti Teknologi Malaysia, for the support in terms of finance and information in the successful completion of this paper.

\section{References}

Abd. Majid, M. Z. (1997). Non-excusable Delays in Constructions. PhD. Thesis. Loughbrough University of Technology. UK:

Ahmad, T. (2003). Delay in Construction Project. Master Thesis, Universiti teknologi Malaysia.

Assaf, S. A., Al-Khalil, M., \& Al-Hazmi, M. (1995). Causes of Delay in Large Building Projects. Journal of Management in Engineering, 11(2), 45-50.

Bartholomew, S. H. (1998). Construction contracting/Business and legal principles. N.J.

Bramble, B. B., \& Callahan, M. T. (1987). Construction Delay Claims. USA: John Wiley \& Sons, Inc.

Geoffrey, M. H. (2006). What Are Institution. Journal of Economic, 40(1).

Hemanta, D., Anil Sawhney, K. C., \& Iyer, S. R. (2012). Analysing Factors Affecting Delays in India Construction Projects. International Journal of project Managemet, 30, 479-489.

Hofstede, G. (1991). Cultures and organizations: Software of the mind. London: McGraw-Hill.

Keith, P. (2005). Delay and Disruption in Construction Contracts (hardback). Informa Business Publishing.

Knight, R., Pascoe, T., \& Henchley, A. (2002). The Forgotten Cost! Watford: Building.

Kraiem \& Diekmann. (1987). Concurrent delays in construction projects. Journal of Construction Engineering and Management, 113(4), 591-602.

Majid, I. A. (2006). Causes and Effect of Delays in Acheh Construction Industry. Master Thesis, Universiti Teknologi Malaysia

MHLG. (2007). Ministry of Housing and Local Government Malaysia.

National Audit Office \& Audit Commission. (2005). Building More Affordable Homes: Improving the Delivery 
of Affordable Housing in Areas of High Demand, Norwich: The Stationery Office

Ng, W. S. (2001). Analysis of Non-Excusable Delays Factors that Influence Contractor's Performance. Master Thesis, Universiti teknologi Malaysia.

Nuhu, B. (2008). An Investigation Into The Use of Construction Delay and Discruption Analysis Methodologies. $\mathrm{PhD}$ Thesis, University of Wolverhampton.

Nunally, J. C. (1978). Psychometric Theory (2nd ed). New York: MaGraw-Hill

Soon, T. K. (2010). Dispute Resolution in Relation to Delay of Construction Project, EFKA. Master Thesis, Universiti Teknologi Malaysia.

Wan, H. (2001). An Investigation of Project Cycles in Malaysia. Project Report. Universiti teknologi Malaysia.

Appendix A

\begin{tabular}{|c|c|c|c|c|c|}
\hline No & $\begin{array}{c}\text { Housing } \\
\text { Delivery } \\
\text { Stages }\end{array}$ & Delay Factors & Structural & Institutional & Cultural \\
\hline 1 & Development & Type of Procurement & 0.604 & & \\
\hline 2 & Approval & Improper Project Feasibility Study & 0.723 & & 0.686 \\
\hline 3 & & Lack of Experience of Consultant & & 0.617 & \\
\hline 4 & & Lack of Experience of Contractor & 0.623 & & \\
\hline 5 & & Communication and Coordination Breakdown & & 0.643 & \\
\hline 6 & & Incompetent Staff in Developer & & 0.64 & \\
\hline 7 & & Incompetent Staff in Consultant & & 0.685 & \\
\hline 8 & & Incompetent Staff in Contractor & & & 0.622 \\
\hline 9 & & $\begin{array}{l}\text { Delays in Municipal Procurement Processes for } \\
\text { Project }\end{array}$ & 0.733 & 0.7 & \\
\hline 10 & & Delays in EIA and NHBRC Approvals & 0.654 & & \\
\hline 11 & & Uncertainty in Statutory Requirements & & 0.869 & \\
\hline 12 & & Numerous Procedures and Departments in LA & 0.646 & 0.736 & \\
\hline 13 & & Political Uncertainty & 0.609 & 0.737 & \\
\hline 14 & & Changes/Amendments in Rules and Regulations & 0.633 & 0.748 & \\
\hline 15 & & Lapses in the Administrations Works and Processes & 0.66 & 0.754 & \\
\hline 16 & & Lack of Staff in LA & 0.701 & 0.772 & \\
\hline 17 & & Long Decision Making Duration & 0.81 & 0.771 & \\
\hline 18 & & Improper Documentation & 0.735 & 0.802 & \\
\hline 19 & & Needs for Approval from Other Department & 0.737 & 0.602 & \\
\hline 20 & & $\begin{array}{l}\text { Lack of HR Resourcing at both Provincial and } \\
\text { Municipal Levels }\end{array}$ & 0.747 & 0.664 & \\
\hline 21 & & Delay in Decision Making by LA & 0.805 & 0.703 & \\
\hline 22 & & Delay in Decision Making by Developer & 0.823 & 0.606 & \\
\hline 23 & & Late Approval in Design & 0.798 & 0.645 & \\
\hline 24 & & Delay in Approval Major Changes & & 0.629 & \\
\hline 25 & & Late in Reviewing and Approving design Documents & 0.754 & 0.791 & \\
\hline 26 & & Misunderstanding of Owner's Requirements & & 0.73 & \\
\hline 27 & & $\begin{array}{l}\text { Late in Revising and Approving Design Documents } \\
\text { by Owner }\end{array}$ & 0.85 & 0.782 & \\
\hline 28 & Construction & $\begin{array}{l}\text { Underestimating the Difficulty and Complexity of } \\
\text { Project }\end{array}$ & & & 0.738 \\
\hline 29 & & Project Financing & 0.69 & & \\
\hline 30 & & Complexity of Project Design & 0.738 & & \\
\hline 31 & & Design Instruments & 0.733 & & \\
\hline 32 & & Obsolete Technology & 0.791 & & \\
\hline 33 & & Delay in Site Mobilization & 0.855 & 0.682 & \\
\hline 34 & & Shortage of Equipment & 0.828 & 0.728 & \\
\hline 35 & & Incompetent Machineries Operator Skill & 0.814 & 0.701 & \\
\hline 36 & & Low Productivity and Efficiency of Equipment & 0.788 & 0.774 & \\
\hline 37 & & Inappropriate Construction Methods & 0.82 & 0.723 & \\
\hline
\end{tabular}




\begin{tabular}{|c|c|c|c|c|c|}
\hline 38 & & Unreliable Subcontractor & 0.854 & & 0.707 \\
\hline 39 & & Site Labors Turnover & 0.873 & & \\
\hline 40 & & Poor Site Management and Supervision & 0.862 & & \\
\hline 41 & & Inaccessibility of Basic Infrastructures & 0.643 & & \\
\hline 42 & & Materials Shortage & 0.839 & 0.645 & 0.627 \\
\hline 43 & & Shortage of Labors & 0.795 & 0.647 & 0.83 \\
\hline 44 & & Poor Professional Management & & & 0.803 \\
\hline 45 & & Poor Time Management & & 0.739 & 0.833 \\
\hline 46 & & Inadequate Facilities & 0.737 & & 0.645 \\
\hline 47 & & Competency of Project Team & & 0.612 & 0.664 \\
\hline 48 & & Insufficient Data/Information & & 0.8 & 0.641 \\
\hline 49 & & Management Staffs Turnover & & 0.699 & \\
\hline 50 & & Delay on Progress Payments & 0.759 & & \\
\hline 51 & & Suspension of Work & 0.767 & & \\
\hline 52 & & Poor Qualification & & 0.647 & 0.663 \\
\hline 53 & & High Tax on Construction & 0.646 & & \\
\hline 54 & & Extra Work Without Approval & 0.772 & & \\
\hline 55 & & Nationality of Labors & 0.851 & & \\
\hline 56 & & Economical Conditions & & 0.619 & 0.651 \\
\hline 57 & & High Interest Rate & & & 0.615 \\
\hline 58 & & Improper Construction Methods Implemented & 0.781 & & \\
\hline 59 & & $\begin{array}{l}\text { Delay in Approving Shop Drawings and Sample } \\
\text { Materials }\end{array}$ & 0.666 & & \\
\hline 60 & & Outdated Engineering Design Software & 0.719 & & \\
\hline 61 & & $\begin{array}{l}\text { Delay, Mistakes and Discrepancies in Design } \\
\text { Documents }\end{array}$ & & 0.61 & \\
\hline 62 & & Unclear and Inadequate Details in Drawings & & 0.682 & \\
\hline 63 & & Change Orders & & 0.706 & 0.701 \\
\hline 64 & & Rigid attitude & & & 0.685 \\
\hline 65 & & Accident During Construction & 0.772 & 0.715 & \\
\hline 66 & & Low Productivity of Labors & 0.81 & 0.767 & \\
\hline 67 & & Poor Communication and Coordination & & 0.745 & 0.707 \\
\hline 68 & & Rework & 0.694 & 0.746 & \\
\hline 69 & & Conflicts & & 0.622 & 0.632 \\
\hline 70 & Handing Over & Lack of Dedicated Focus and Assurance & & & 0.683 \\
\hline 71 & & Lack of Technical Over-Sight Capabilities & & 0.638 & 0.677 \\
\hline 72 & & Legal Dispute & 0.668 & & 0.636 \\
\hline 73 & & Inadequate Definition of Substantial Completion & 0.792 & & \\
\hline 74 & & $\begin{array}{l}\text { Delay in performing final inspection and certification } \\
\text { by a third party }\end{array}$ & 0.803 & & \\
\hline 75 & & Handover Packaging & 0.899 & & \\
\hline 76 & & Appliances Defects & 0.876 & & \\
\hline 77 & & Delay in Performing Inspection and Testing & 0.77 & & \\
\hline 78 & & $\begin{array}{l}\text { Unavailability of incentives to contractor for finishing } \\
\text { ahead of schedule }\end{array}$ & 0.84 & & 0.736 \\
\hline
\end{tabular}




\section{Appendix B}

\begin{tabular}{|c|c|c|c|c|c|}
\hline No & $\begin{array}{c}\text { Housing } \\
\text { Delivery } \\
\text { Stages }\end{array}$ & Delay Factors & Structural & $\begin{array}{l}\text { Institutio } \\
\text { nal }\end{array}$ & Cultural \\
\hline 1 & Development & Uncertainty in Statutory Requirements & & 0.869 & \\
\hline 2 & Approval & Long Decision Making Duration & 0.81 & 0.771 & \\
\hline 3 & & Improper Documentation & 0.735 & 0.802 & \\
\hline 4 & & Delay in Decision Making by LA & 0.805 & 0.703 & \\
\hline 5 & & Delay in Decision Making by Developer & 0.823 & 0.606 & \\
\hline 6 & & Late in Revising and Approving Design Documents by Owner & 0.85 & 0.782 & \\
\hline 7 & Construction & Delay in Site Mobilization & 0.855 & 0.682 & \\
\hline 8 & & Shortage of Equipment & 0.828 & 0.728 & \\
\hline 9 & & Incompetent Machineries Operator Skill & 0.814 & 0.701 & \\
\hline 10 & & Inappropriate Construction Methods & 0.82 & 0.723 & \\
\hline 11 & & Unreliable Subcontractor & 0.854 & & 0.707 \\
\hline 12 & & Site Labors Turnover & 0.873 & & \\
\hline 13 & & Poor Site Management and Supervision & 0.862 & & \\
\hline 14 & & Materials Shortage & 0.839 & 0.645 & 0.627 \\
\hline 15 & & Shortage of Labors & 0.795 & 0.647 & 0.83 \\
\hline 16 & & Poor Professional Management & & & 0.803 \\
\hline 17 & & Poor Time Management & & 0.739 & 0.833 \\
\hline 18 & & Insufficient Data/Information & & 0.8 & 0.641 \\
\hline 19 & & Nationality of Labors & 0.851 & & \\
\hline 20 & & Low Productivity of Labors & 0.81 & 0.767 & \\
\hline 21 & Handing Over & Delay in performing final inspection and certification by a third party & 0.803 & & \\
\hline 22 & & Handover Packaging & 0.899 & & \\
\hline 23 & & Appliances Defects & 0.876 & & \\
\hline 24 & & $\begin{array}{l}\text { Unavailability of incentives to contractor for finishing ahead of } \\
\text { schedule }\end{array}$ & 0.84 & & 0.736 \\
\hline
\end{tabular}

\section{Copyrights}

Copyright for this article is retained by the author(s), with first publication rights granted to the journal.

This is an open-access article distributed under the terms and conditions of the Creative Commons Attribution license (http://creativecommons.org/licenses/by/3.0/). 